\title{
Sidewall roughness measurement of photonic wires and photonic crystals
}

\author{
Svalgaard, Mikael; Frandsen, Lars Hagedorn; Garnæs, Jørgen; Kühle, A.
}

Published in:

European Conference on Lasers and Electro-Optics, 2007 and the International Quantum Electronics Conference. CLEOE-IQEC 2007.

Link to article, DOI:

10.1109/CLEOE-IQEC.2007.4386571

Publication date:

2007

Document Version

Publisher's PDF, also known as Version of record

Link back to DTU Orbit

Citation (APA):

Svalgaard, M., Frandsen, L. H., Garnæs, J., \& Kühle, A. (2007). Sidewall roughness measurement of photonic wires and photonic crystals. In European Conference on Lasers and Electro-Optics, 2007 and the International Quantum Electronics Conference. CLEOE-IQEC 2007. (pp. 1-1). IEEE. https://doi.org/10.1109/CLEOEIQEC.2007.4386571

\section{General rights}

Copyright and moral rights for the publications made accessible in the public portal are retained by the authors and/or other copyright owners and it is a condition of accessing publications that users recognise and abide by the legal requirements associated with these rights.

- Users may download and print one copy of any publication from the public portal for the purpose of private study or research.

- You may not further distribute the material or use it for any profit-making activity or commercial gain

- You may freely distribute the URL identifying the publication in the public portal 


\title{
Sidewall Roughness Measurement of Photonic Wires and Photonic Crystals
}

\author{
M. Svalgatard, L.H. Frandsen \\ Department of Communications, Optics \& Materials, \\ Technical University of Denmark, DK-2800 Lyngby, Denmark. \\ J. Games, A. Kuhle \\ Danish Fundomental Metrology Ltd, \\ Technical University of Denmark, DK-2800 Lyngby, Denmark.
}

The performance of nanophotonic building blocks such as photonic wires and photonic crystals are rapidly improving, with very low propagation loss and very high cavity Q-factors being reported [1]. In order to facilitate further improvements in performance the ability to quantitatively measure topological imperfections such as sidewall roughness on a sub-nm scale becomes essential [2]. In this paper we use atomic force microscopy (AFM) on tilted samples to obtain the most detailed sidewall roughness measurements yet on nanophotonic structures.

a)

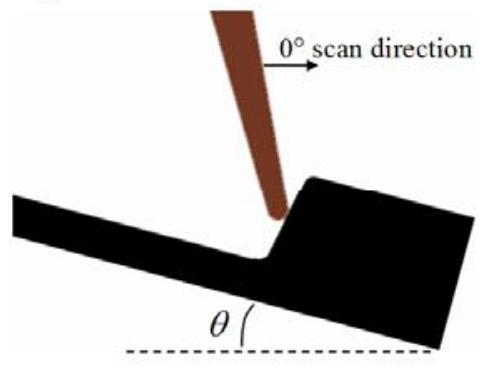

b)

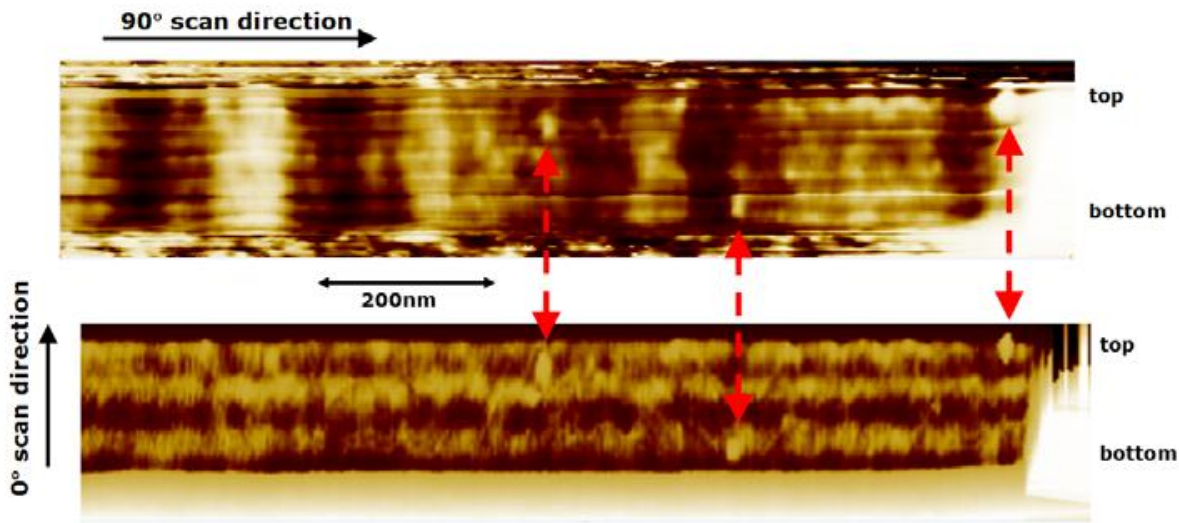

Fig. 1: (a) AFM measurement geometry with $0^{\circ}$ scan direction indicated; (b) Roughness features along two directions of a $1.2 \mu \mathrm{m}$ long, linear sidewall section in GaAs. Point-like defects common to both measurements are indicated by arrows.

The measurements were performed using a tapping mode AFM on samples that could be tilted up to $20^{\circ}$ to better sample near-vertical sidewalls (fig. 1a). The AFM tip used here had a $1.5 \mu \mathrm{m}$ long extension with a $5^{\circ}$ half-cone angle and a tip radius $<15 \mathrm{~nm}$ (Nanosensors Inc.). An example of a measurement on a $150 \mathrm{~nm}$ deep, linear sidewall in GaAs is shown in fig. 1b. Due to slow drift and line-wise distortions, roughness is best revealed along the fast-scan direction: in our case either perpendicular $\left(0^{\circ}\right)$ or parallel $\left(90^{\circ}\right)$ to a sidewall, as seen from above. A long the $0^{\circ}$ scan direction a number of nearly equidistant bands are revealed which match the cyclic GaAs etching used during fabrication. The $90^{\circ}$ scan direction reveals a less uniform, curtain-like pattern which is likely associated with roughness of the etch mask. Point-like defects are common to both measurement directions, examples are indicated by red arrows. The roughness features shown here extend roughly $\pm 1.5 \mathrm{~nm}$ normal to the slope surface. For $160 \mathrm{~nm}$ diameter holes in a photonic crystal similar results were obtained, however the small hole size lead to scanning artifacts from probe - meniscus lay er interactions so that measurements could only be done near the hole center-line.

The measurements presented here represent, to the best of our knowledge, the highest resolution and most quantitative assessment y et of sidewall roughness in photonic wires and photonic crystals. The technique of tilted AFM is non-destructive in nature and can reveal both point-like defects, vertical curtains and horizontal bands which can be related to various fabrication steps which is essential for further optimization of device performance.

\section{References}

1. B.-S. Song et al., Nature Materials, 4, 207-210(2005)

2. E. Kuramochi et al., Phys. Rev. B 72, 161318(R) (2005) 